\title{
Promoting Fusion in the Business-IT Relationship
}

\author{
Nina Evans \\ Tshwane University of Technology, Pretoria, South Africa
}

\author{
evansa@tut.ac.za
}

\begin{abstract}
Failed Information Technology (IT) projects are common in organisations, as IT solutions often do not meet the expectations of business clients. Business experts often have a negative perception of the people working in the IT function. There seems to be a proverbial "chicken-and-egg situation": the relationship between business and IT suffers because IT projects fail to solve the real business need and, on the other hand, many IT projects fail because of existing interpersonal relationship problems between business- and IT employees.

Research was done to identify categories of issues in the business-IT interface and rank them in order of significance. The term "fusion" is used in this paper, to refer to the process by which the elements of the IT function and the rest of the business work together to achieve a common goal. This paper reports on the categories of issues and draws a conclusion of what would constitute fusion in the business-IT interface.
\end{abstract}

Keywords: Information technology/systems, business-IT interface, expectation gap, business-IT relationship, strategic alignment, fusion

\section{Introduction}

Research projects to quantify the success rate of IT projects found a high percentage of unsuccessful information systems in organisations. The criteria for success of IT projects are that they are delivered on time, within (or below) budget and that the systems work as required. Failures include extended schedules, exceeding the budget and failing to meet stakeholder needs. Business expects IT professionals to solve their business problems, but Burris (1999) is of the opinion that "the gap between how IT executives think they are performing (against business expectations) and how they are really performing (based on CEO perceptions) is widening". According to the Standish group's CHAOS report of 2000, $26 \%$ of software projects succeed, which means that 74\% fail. Mann (2002) is of the opinion that more than a third of all software projects exceed their budgeted cost and time schedule. Some are abandoned in midstream. The high rate of failure of IT projects are sources of concern for the modern organisation, because it is increasingly dependent on the effective and efficient implementation of IT in all areas of the organisation.

In most instances the lack of confidence in IT is not focused on the technology - it is aimed at the IT professional. Business experts have a negative perception of the IT function. The business sec-

Material published as part of this journal, either on-line or in print, is copyrighted by Informing Science. Permission to make digital or paper copy of part or all of these works for personal or classroom use is granted without fee provided that the copies are not made or distributed for profit or commercial advantage AND that copies 1) bear this notice in full and 2) give the full citation on the first page. It is permissible to abstract these works so long as credit is given. To copy in all other cases or to republish or to post on a server or to redistribute to lists requires specific permission from the publisher at Publisher@InformingScience.org tions regard IT professionals as 'strange' and 'part of the problem'. According to Aggarwal (1996) the credibility of information systems personnel suffer because they cannot meet the expectations of the users. Users therefore have a negative impression that systems staff cannot get anything done on time and within 
budget. Because of the negative image, user support for future projects becomes increasingly difficult. Fielding (2002) agrees that most IT departments are still "held in very low esteem". They need to build personal relationships and "be caught doing things right".

Kunda (2001) agrees that the major cause of most software failures is the people rather than the technology. He suggests that the factors, which should be addressed during software development are: political issues, organisational and business strategy, organisational resources and support, organisational setting and management style, and organisational culture. The relationship gap refers to stereotypes, which originate when two groups do not interact frequently and effectively and the prejudgements of the other group are never checked. Logan (2002) supports this by saying: "too many companies fail to recognise the cultural differences between business managers and IT professionals and therefore fail to take steps to bridge those differences." Cormack (2001) also attributes tension in the relationship to different issues, of which many are related to the organisational culture and interpersonal relationships. Examples of such issues include horror stories, poor communication, misuse of expert power and position power, low interdependence and the lack of clear control. Research therefore has to move towards the human element of IT and the cultural differences between business and IT groups. Katz (1995) suggests that the negative perceptions of the IT function can be changed and that, instead of "being part of the problem, not the solution and not understanding the business", IT professionals should become part of a reengineering effort and focus on "forging new working relationships and repairing old ones". Business considerations, not technical ones, should drive investments in IT.

A topic of many research projects is the need for strategic alignment between IT and business. Important researchers in this field include Henderson (1998), Henderson and Venkatraman (1991), Hirscheim (2001), Meador (1999) and Luftman (2001). These researchers and practitioners have studied and described strategic alignment as a means for ensuring that IT management actions are consistent with the business strategy, ensuring that the "capabilities, structures and processes of the IT organisation reflect and enable the business capabilities, structures and processes." A strategic alignment model was developed in the 1980s and improved over the years. As the model was developed at a time when the business environment was more stable, it casts IT in a mere supporting role in business strategy.

Bridging the gap between IT units and business units through strategic alignment implies that the IT strategy follows business strategy. This traditional alignment approach is not enough to ensure successful IT implementations. The problem is that the alignment concept is about a sequential development of strategies and a sequential operationalisation. A lack of IT agility and responsiveness can create a competitive disadvantage and therefore the sequential model is simply too slow. Smaczny (2001) supports this in saying: "owing to major market changes, the strategic alignment model no longer provides companies with the much-needed answers" and "a strategy approach which allows for handling a fast-changing environment and rapid response is needed". Rather than settle for alignment, companies should aim for fusion (Luftman, 2000). According to the Oxford dictionary, fusion means:

fusion\'fyü-zh : 1. A merging of divorced, distinct, or separate elements into a unified whole. 2. A union of particles that result in the release of enormous quantities of energy.

No organisation can exist unless there is a strong common purpose among its people. The classic example is a rowing boat: it's impossible to go anywhere if the rowers row in different directions. The importance of alignment on lower levels and the human element of alignment (within groups and individual jobs) should therefore not be underestimated. This emphasises the importance of healthy interpersonal relationships between, amongst others, manager/IT employee, IT professional/client, outsourcing partners and project teams. Fusion can be seen as the process by which people connect and add their energies to each other to achieve a goal. Britt (2002) says that posi- 
tive energy has to be generated by fusion, not just friction. He believes that "fostering a truly collaborative partnership between business and IT requires a different mindset - for the IT organisation as well as the business. Business and IT leaders must feel comfortable crossing over into one another's domain and build successful, ongoing relationships.

\section{The Research}

This paper describes part of a research project to develop a framework for creating fusion between business and IT within organisations.

\section{Rationale and Motivation behind the Research}

For any country to play a role in the world of technology and computing, it is essential that institutes for higher education produce young individuals who are both technologically literate and well rounded, and who will play an important role in bringing together business and IT. To effectively manage the academic programs and make changes to instructional offerings, institutions must have access to various sources of information. It is thus necessary to launch in-depth investigations (formal research) into the needs of a representative number of ICT companies and to create and maintain close links with the ICT industry.

It is the responsibility of educational institutions, to extract the necessary information from the industry, rather than expecting industry to feed them the information. To understand how the profession of the IT worker has changed, the changing technologies, the changing business environment and the changing role of ICT in organisations (all factors which bring about changes in the profile of the ICT worker) have to be investigated.

\section{Research Methodology}

Since the general shift in IT research, away from technological to managerial and organisational issues, there has been an increasing interest in qualitative research in this field. The goals of such qualitative analysis are the discovery of regularities, patterns and themes and the comprehension of the meaning of text or action. The challenges of the qualitative data analysis for this study were the following.

- There was a large amount of data, which had to be reduced to meaningful and manageable amounts by coding/classifying the data.

- The data collected varied in its relevance.

- There were no simple facts or figures.

- There was a need to identify themes/patterns in order to develop the analysis. (Miles, 1994).

\section{Research Design}

The research focused on companies in Gauteng, South Africa and consisted of three parts:

1. An in-depth literature study to determine the reasons for project failure and an adverse business-IT relationship ("non-fusion").

2. A survey to determine the industry's perceptions of this gap between business clients and the IT function.

3. The most important role-players in promoting business-IT fusion.

This article describes the results of parts one and two only. 
The most important issues of the business-IT gap and the major reasons for non-fusion were determined from literature and the related issues were classified into 25 categories. A questionnaire was designed and personal interviews conducted with both business- and IT managers, to determine the significance of the various issues. A five-point Likert scale, ranging from 'very significant' to 'not significant at all' was used. Some of the comments made by the participants during the interviews are reported here, in conjunction with the results from the questionnaire. Amongst others, the participants were invited to comment on their perception of the degree of strategic alignment in their organisation, and whether or not the IT manager is part of the board of directors and plays an active part in the decision-making process. The term fusion was also discussed to determine whether it is used in their organisations.

Fourth-year IT students at the Tshwane University of Technology were involved in conducting the interviews as part of the IT management (ITA401A) course. Students had to set up appointments with managers and use the structured interview method of gathering the necessary information. Learners gained valuable exposure to the ICT industry and received information about business-IT relationship issues "straight from the horse's mouth". This research experience will also prove valuable, should they become involved in post-graduate studies and research projects. Before conducting the interviews, students were briefed on the contents of the questionnaire, the potential complications of setting up and conducting interviews and the format in which the results had to be presented to the researcher. The researcher verified the authenticity of the results with the participants.

\section{Section 1 : Business-IT gap}
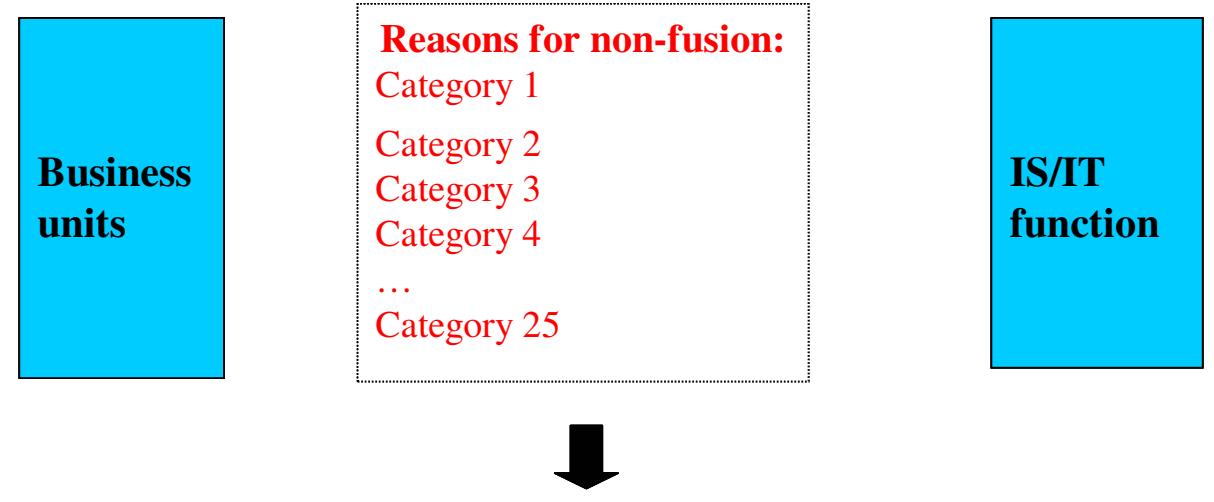

Fusion

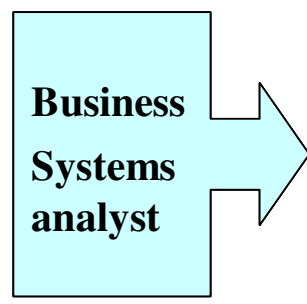

Section 3.1

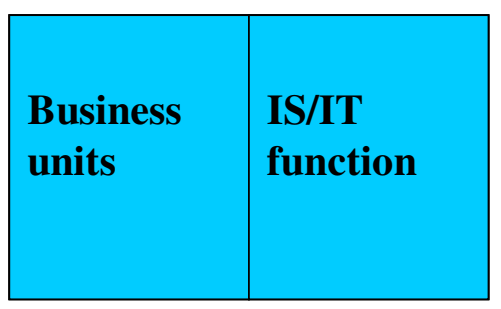

Section 2

Elements of fusion

(What constitutes fusion in the business-IT interface?)

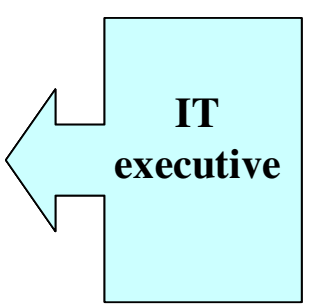

Section 3.2

Figure 1: The Framework 


\section{The Framework}

Figure 1 illustrates the framework. Section one of the framework consists of the reasons for the business-IT gap and section two describes the elements of fusion in the business-IT interface. These two sections are described in this paper. (Section 3.1 and 3.2 refers to two important roleplayers in creating fusion, namely the analyst and IT executive. This part of the project is not covered in this paper.

\section{Results: The Business-IT Relationship}

\section{The Reasons for Non-fusion}

Most organisations have limited knowledge of the factors contributing to the success or failure of their Information Technology projects. An interpretation of the referenced literature sources indicates that there are many reasons for IT project failure. The relationship between business and IT is bad because IT projects fail to fulfil the real business need. However, in many cases the IT projects fail simply because there is a bad relationship between business and IT. It seems that we have the proverbial chicken-and-egg situation where the one is the cause of the other and no one knows which one came first.

All 191 different reasons for failure of IT projects and/or an adverse relationship between business and IT, which were obtained from literature sources were summarised and duplicates were removed. The related issues were subsequently classified into the following 25 categories:

1. The real business need is not understood (ineffective requirement specification)

2. Project scope changes (changing business needs/technology)

3. Insufficient client expectation management

4. Lack of communication

5. Poor documentation practices

6. Testing

7. People issues/behavioural issues/cultural issues

8. Adverse interpersonal relationships

9. Lack of business ownership/collaboration

10. Lack of shared goals

11. Negative attitude towards the IS/IT function

12. Lack of strategic alignment

13. Strategic role/involvement of IT manager

14. Skills, attributes and attitudes of IT personnel

15. Lack of shared responsibility

16. Insufficient equipment and infrastructure

17. Lack of senior management involvement

18. Lack of knowledge transfer between IT and the business

19. Different measures of success

20. Management issues: organisation/business management 
21. Management issues: IT management

22. Project-specific issues

23. Project management issues

24. Project manager issues

25. Finances

\section{Ranking of Categories}

67 IT managers and 48 business managers from 67 different companies completed the questionnaire and agreed to participate in personal interviews. The 25 categories were listed separately at the end of the questionnaire and the respondents were asked to identify and rank the ten most significant categories in descending order of importance (1- most significant; 10- least significant). Out of the 25, the following ten categories were selected as 1 to 5 in significance by the largest percentage of respondents (1-highest percentage):

\section{IT managers:}

1. Lack of communication

2. Lack of strategic alignment

3. People issues/behavioural issues/cultural issues

4. Strategic role/involvement of IT manager

5. Skills, attributes and attitudes of IT personnel

6. Lack of knowledge transfer between IT and the business

7. Negative attitude towards the IS/IT function

8. Adverse interpersonal relationships

9. Project manager issues

10. Management issues: IT management

\section{Business managers:}

1. Lack of communication

2. Lack of knowledge transfer between IT and the business

3. Lack of strategic alignment

4. People issues/behavioural issues/cultural issues

5. Negative attitude towards the IS/IT function

6. Skills, attributes and attitudes of IT personnel

7. Strategic role/involvement of IT manager

8. Project manager issues

9. Adverse interpersonal relationships

10. Management issues: IT management

Business managers and IT managers rated almost exactly the same categories of issues as important. The lack of communication, scope changes, lack of shared goals and responsibilities, lack of 
strategic alignment and financial constraints are most important. Business managers rated 'The real business need is not understood and solved' as the most significant and they also believe the expectations of clients and users are not managed well. This is closely linked to the category 'Different perceptions of the measures of success', where business managers indicate that IS/IT might think the project was a success, whereas the business side is disappointed in the result. On the other hand, business managers do realise that scope change is a major contributor towards the failure of IS systems. Business managers are also concerned about the lack of knowledge transfer between the IS and business experts. This is an indication that they don't understand the world of IS/IT. Furthermore, the business managers did not rate insufficient skills, attributes and abilities of IT personnel as under the ten most significant issues, whereas IT managers believe it is an important contributor towards IS/IT project failure.

IT managers believe the user is not involved enough and that people issues have a significant influence on the success of projects and the relationship between business and IT. This supports the notion that IT people are not naturally good at managing people issues and organisational politics. It is also a problem if the IT manager is not a member of the board of directors and therefore has no say in the overall strategy of the organisation.

\section{Interview Comments}

During the personal interviews, the participants elaborated on the questionnaire and participated in a general discussion concerning the relationship and alignment between IT and the remaining functions of the business. Direct quotes are shown in italics. It was perceived that top management do not really see IT professionals as real people. ("They don't treat them as humans.") The business department sees IT as a never-ending drain on the bottom line that is fighting against the business. "Business and IT people don't work together constructively."

There is a problem of work overload and insufficient training. "Some of the technology is too complex for business managers to understand entirely. Insufficient resources can lead to project failure. One problem is that the permanent staff is not valued as they should be. Some business people don't understand the full potential of the IT capabilities in the sense of what is possible and what is not."

The lack of knowledge inside the organisation also causes many conflicts, as does the fact that they do not really operate entirely as a team. "The CIO doesn't in fact take up the position to fill the gap between IT and business." On strategic alignment, one participant commented: "Our organisation is an IT organisation. Our core business is providing IT solutions outside the organisation. It is therefore of paramount importance for the IT strategy to align itself to the business strategy, otherwise the company would not exist. Traditionally it was not important."

The participants were also asked whether the IT manager/CIO of their company is part of the board of directors and therefore plays an active part in formulating the organisational strategy. Some participants agreed: "Our company regard the IT manager as the most important person within its endeavour to achieve business, hence the IT manager is part of the strategic planning team and does participate fully." Others disagreed: "The CIO is not a member of the

board/EXCO (Executive Committee). However, he reports directly to the financial director, who is a senior member of the board. As and when required, the CIO will participate (on the board's request or on his own request) in EXCO meetings on matters of concern."

In addition to the above the principle of fusion was discussed. Less than a third of the interviewees indicated that they've heard the term fusion used in this context, but they guessed what was meant by this term: "Fusion between business and IS/IT entails a strategic, financial and operational integration between units. It will be necessary for these units to remain objective towards each other and maintain synergy towards achieving common goals. There should be constant 
communication between units to stimulate new ideas that will result in greater productivity." To one business manager fusion means that "the two departments must function as an integrated whole and that both parties must operate in unison, understanding the needs of the one and the capabilities of the other". He is of the opinion that to create the necessary fusion, "joint development on an IT vision and building trust between the parties involved based on a proper service level agreement" are important.

The service delivery manager responsible for delivering IT services at a large company said:

"Had I completed this questionnaire a year ago, it would have looked a lot different. Only now do we recognise the importance of successful fusion between IS and business."

\section{The Elements of Fusion}

From the literature and survey results the criteria for fusion between business and IT that were identified are shown in Table 1.

\section{Table 1: Criteria for fusion}

The IT department and the business client have the same goals

Both the business and IT representatives take responsibility for project success

Users are involved in the problem definition, planning and design

The IT function solves the real business need, not only what they perceive as the need

Business clients and IT professionals understand each other's worlds and speak a common language

Business clients and IT professionals have realistic expectations of the other's performance

Clear communication between the parties

Effective documentation

Effective and timely testing, involving the client

Interpersonal relationships based on trust, empathy and respect

The business strategy and the business strategy are developed to support each other

Knowledge transfer from one project to the next

Management involvement and good leadership - which is supportive of change and technological advancement - on both top management and project management levels

An organisational culture which is supportive of technology

IT leaders who understand and accommodate the unique characteristics of the IT and the IT professional

\section{Summary and Conclusions}

This research focused on the business-IT interface and aimed to investigate the gap between the two stakeholder groups (business and the IS/IT function). There are many categories of reasons 
for the business-IT expectation gap. The traditional model of strategic alignment is not enough to close the gap. A linear process of creating the business strategy with the IT strategy following it is not enough to ensure successful IT implementations. The strategic alignment model therefore no longer provides companies with the correct answers to the problems in a fast-changing environment such as ICT. A new approach is needed - a higher level of alignment, also termed fusion by a few researchers and practitioners. Such fusion has to be achieved on all levels of the organisation (strategic, tactical and operational).

Fusion between the customer (client/end user) and the IT professionals will only materialise if:

- The needs of the client are solved by means of an IT implementation. For this it is necessary that the real need is identified and documented properly before the solution is designed, coded and implemented.

- Successful ongoing 'partnerships' are forged between the IT function and business units, as are interpersonal relationships between the various stakeholders in the IT/business relationship. This would result in a learning organisation where the user and the technical specialist understand each other's world and share responsibility for the success of IT implementations. Such healthy relationships would lead to greater customer value and profitability.

\section{References}

Aggarwal, R \& Rezaee, Z. (1996). Total quality management for bridging the expectations gap in systems development. International journal of Project Management, 14(2).

Britt, F.F. (2002). Multiplying business value: The fusion of business and technology. IBM Institute for Business Value. USA.

Burris, P. The IT-to-Business Value Gap. META Group Inc. [Online]. Available at http://www.bitpipe.com.

Cormack, S, et al. (2001). Resolving the troubled IT-Business relationship from a Cultural perspective. Proceedings of the twelfth Australasian Conference on Information Systems.

Fielding, R. IT projects doomed to failure. (2002). [Online]. Available at http://www.computing.co.uk.

Henderson, J. \& Venkatraman, N. (1991). Strategic Alignment: A Model for Organisational Transformation Via Information Technology. Working Paper 3223-90, Cambridge, MA : Sloan School of Management, MIT.

Hirschheim, R. \& Sabherwal, R. (2001). Detours in the Path towards Strategic Information Systems Alignment. California Management review, 44(1), 87-109.

Katz, M. \& Tucker, J. (1995). Forging Good Relationships. InformationWeek, (518), 96.

Kunda, D. \& Brooks, L. Human, Social and Organisational Influences on Component-based Software Engineering. Carnegie Mellon University. [Online]. Available at http://www.sei.cmu.edu

Logan, J. (2002). Can't We All Just Get Along? Optimise Magazine, (9).

Luftman, J. (2000). Assessing Business/IT Alignment Maturity. School of Management: Stevens Institute of Technology.

Mann, J. (2000). IT Education's Failure to Deliver Successful Information Systems: Now is the Time to Address the IT-User Gap. Journal of Information Technology Education, 1(4).

Meador, C.L. IT/Strategy Alignment. Working Paper No. 9403. MIS Quarterly. Available at [http://www.it-consultancy.com/background/ alignment].

Smaczny, T. Is an alignment between business and information technology the appropriate paradigm to manage IT in today's organisations? Management Decision, 39(10), p797-802. 


\section{Biography}

Dr. Nina Evans started her career as a Chemical Engineer after graduating from the University of Pretoria in 1982. She registered as a professional engineer (PrEng) and worked as a Research and Development engineer for five years. During this time she completed the Higher Education Diploma (HED), followed by the Diploma in Datametrics, with Computer Science as the major third year subject at the University of South Africa. She then joined the Department of Computer Data Processing at Technikon Pretoria as a lecturer. Two years later she completed a BSc (Hons) degree in Computer Science Cum Laude at the University of Pretoria. She lectured in many aspects of computing, including programming (C, C++ and Delphi), systems software and operating systems. As Head of the Department of Computer Technology she completed a research project to determine the profile of the Knowledge and Information Technology worker in a changing organisational environment and its impact on the Technikon Information Technology training programs. For this research she received the MTech(Information Technology) degree from Technikon Pretoria . In January 2000 she was awarded a bursary for Masters level study at any Australian university by the former president of South Africa, Mr Nelson Mandela and chose to enrol for an MBA degree at Bond University. She completed the degree in September 2001 with an average of $80 \%$.

In 2003 she completed $\mathrm{PhD}$ degree in Organisational Behaviour from the University of Pretoria. The coursework focused on individual behaviour, group/team behaviour and organisational structures and included subjects like Research Methodology, International Management, Organisational Development, Diversity Management and Virtual Organisations. The title of the dissertation is: "A framework for creating fusion in the business-IT relationship". This study focused on the role-players in the business-IT interface and their impact on the business-IT relationship towards fusion. In January 2004 she received a research grant from the National Research Foundation for further research in this field.

She currently manages the academic programs and personnel of the department Business Applications and IT Management in the faculty of ICT of Tshwane University of Technology. The focus areas of the department are business analysis, project management, business information systems, knowledge management, e-commerce, business management, personal and professional development of IT students/ employees, IT management and strategic management. She also lectures in the fourth year subjects on Business Management, Business Fundamentals, Information and Technology Management and Strategic Information Systems. 